\title{
MERANCANG MODEL PENJADWALAN SHIFT KERJA RESEPSIONIS HOTEL DENGAN MENGGUNAKAN METODE GOAL PROGRAMMING (Studi Kasus: Swiss BelHotel Palu)
}

\author{
S. Prahasti ${ }^{1}$, R. Ratianingsih ${ }^{2}$, A. Sahari ${ }^{3}$ \\ 1Program Studi Matematika Jurusan Matematika FMIPA Universitas Tadulako \\ Jalan Soekarno-Hatta Km. 09 Tondo, Palu 94118, Indonesia. \\ 1syafiraprahasti@yahoo.com, 2ratianingsih@yahoo.com, 3agus sh@yahoo.com
}

\section{ABSTRACT}

The receptionist has an important role in the smooth operation of the hotel. Therefore, it takes high working hours by receptionist who must always be ready on duty 24 hours per day. However, amount of receptionist to much is not the solution to such problem. Optimization of existing human resources is selected by the management hotel to keep the quality of hotel services, such as by maximizing the receptionist scheduling. In this research would made one shift scheduling model using goal programming method, the method is combines one or several objective functions into an objective function. This research results scheduling models that uses goal programming method with the objective function is $X \mathrm{x}_{\mathrm{i}, \mathrm{j}}+\mathrm{Xs}_{\mathrm{i}, \mathrm{j}}+\mathrm{Xm}_{\mathrm{i}, \mathrm{j}} \leq 1, \mathrm{Xm}_{\mathrm{i}, \mathrm{j}}+\mathrm{Xp}_{\mathrm{i}+1, \mathrm{j}} \leq 1, \mathrm{Xp}_{\mathrm{i}, \mathrm{j}}+\mathrm{Xp}_{\mathrm{i}, \mathrm{j}+1}+$ $\mathrm{Xp}_{\mathrm{i}, \mathrm{j}+2}+\mathrm{Xp}_{\mathrm{i}, \mathrm{j}+3} \leq 1, \sum_{\mathrm{i}=1}^{3} \mathrm{Xp}_{\mathrm{i}, \mathrm{j}}+\sum_{\mathrm{i}=1}^{3} \mathrm{Xs}_{\mathrm{i}, \mathrm{j}}+\sum_{\mathrm{i}=1}^{3} \mathrm{Xm}_{\mathrm{i}, \mathrm{j}} \geq 2$ where $\mathrm{Xp}_{\mathrm{i}, \mathrm{j}}$ is the $\mathrm{j}$ receptionist team to work for the morning shift on $\mathrm{i}$ day, $\mathrm{Xs}_{\mathrm{i}, \mathrm{j}}$ is the $\mathrm{j}$ receptionist team to work for the afternoon shift on $\mathrm{i}$ day and $\mathrm{Xm}_{\mathrm{i}, \mathrm{j}}$ is the $\mathrm{j}$ receptionist team to work for the night shift on $\mathrm{i}$ day. Than the models will be solved using LINDO to obtain optimal shift schedule of receptionist.

\section{Keywords : Goal Programming, Receptionist, Scheduling}

\section{ABSTRAK}

Resepsionis mempunyai peran penting dalam kelancaran operasi hotel. Oleh sebab itu dibutuhkan jam kerja yang tinggi oleh resepsionis hotel yang harus selalu siap bertugas 24 jam per hari. Namun, jumlah resepsionis yang banyak bukanlah solusi dari permasalahan ini. Pengoptimalan sumber daya manusia yang ada dipilih sebagian besar pihak manajemen hotel untuk tetap menjaga kualitas pelayanan hotel, diantaranya dengan memaksimalkan penjadwalan resepsionis. Pada penelitian ini akan dibuat suatu model penjadwalan shift resepsionis menggunakan metode Goal Programming, suatu metode yang menggabungkan satu atau beberapa fungsi tujuan menjadi sebuah fungsi tujuan. Penelitian ini menghasilkan model penjadwalan menggunakan metode Goal Programming dengan fungsi tujuan $X p_{i, j}+X s_{i, j}+X m_{i, j} \leq 1, X m_{i, j}+X p_{i+1, j} \leq 1, X p_{i, j}+X p_{i, j+1}+$ $X p_{i, j+2}+X p_{i, j+3} \leq 1, \sum_{i=1}^{3} X p_{i, j}+\sum_{i=1}^{3} X s_{i, j}+\sum_{i=1}^{3} X m_{i, j} \geq 2$ dengan $X p_{i, j}$ adalah tim resepsionis $j$ bertugas untuk 
shift pagi pada hari $i, X s_{i, j}$ adalah tim resepsionis $j$ bertugas untuk shift sore pada hari $i$ dan $X m_{i, j}$ adalah tim resepsionis $j$ bertugas untuk shift malam pada hari $i$. Kemudian model-model tersebut akan diselesaikan menggunakan LINDO sehingga diperoleh jadwal shift kerja resepsionis hotel yang optimal.

\section{Kata kunci : Goal Programming, Penjadwalan, Resepsionis}

\section{PENDAHULUAN}

Penjadwalan adalah permasalahan yang sangat rumit dan sering terjadi pada instansiinstansi yang beroperasi selama 24 jam per hari, salah satunya adalah Hotel. Di hotel, penjadwalan resepsionis merupakan salah satu penjadwalan yang sangat rumit. Hal ini disebabkan karena sering kali pembagian shift yang ada kurang memperhatikan kebutuhan petugas resepsionis. Selain itu sering kali pembagian shift dirasa kurang adil antara resepsionis satu dengan resepsionis yang lain.

Resepsionis adalah orang yang bertugas sebagai penerima tamu disuatu perusahaan, kantor, hotel (Agustina, 2012) [1]. Resepsionis hotel memiliki tugas, pokok dan fungsi dalam pelayanan pemesanan kamar, penanganan barang-barang tamu, tempat informasi, kasir dan lain sebagainya. Oleh sebab itu dibutuhkan jam kerja yang tinggi oleh resepsionis hotel yang harus selalu siap bertugas pada shift yang berbeda yaitu pada shift pagi, sore dan malam. Untuk mengatasi hal tersebut diperlukan persiapan yang matang dalam pengaturan penjadwalan untuk resepsionis. Hal itu diperlukan agar tidak terjadi kelelahan dan keletihan secara fisik, emosi, dan psikologis pada resepsionis yang nantinya akan memberikan dampak buruk bagi kinerja resepsionis dalam memberikan pelayanan pada tamu.

Untuk itu pada tugas akhir ini, akan diterapkan suatu formulasi matematika dengan menggunakan metode Goal Programming (GP) untuk membuat sistem penjadwalan resepsionis hotel yang lebih optimal sehingga diharapkan mampu memberikan informasi pada para pengambil keputusan di hotel agar dapat melakukan penjadwalan menjadi lebih efektif dan efisien. Metode Goal Programming sendiri adalah metode pemrograman tujuan ganda dan merupakan solusi yang dapat dicapai secara optimal pada waktu yang bersamaan berdasarkan kendala-kendala yang dimiliki (Soekartawi,1995) [2].

\section{METODE PENELITIAN}

\subsection{Studi Pustaka}

Melakukan studi pustaka dengan mengumpulkan materi dari berbagai sumber seperti buku, jurnal dan internet. 


\subsection{Tahap Identifikasi}

Tahap identifikasi meliputi penentuan tujuan penelitian, survey pendahuluan, tinjauan pustaka, identifikasi metode analisis dan identifikasi sampel penelitian serta merumuskan masalah yang akan diteliti.

\subsection{Mengumpulkan data}

Data yang diperoleh dari penelitian ini merupakan data sekunder, berupa jumlah resepsionis Swiss-Belhotel, jumlah resepsionis yang bertugas pada masing-masing shift dan jumlah total hari kerja resepsionis. Data lainnya adalah data penjadwalan resepsionis yang sementara digunakan oleh pihak hotel dalam satu bulan namun yang digunakan sebagai bahas analisis adalah jadwal dalam jangka waktu 3 hari.

\subsection{Penerapan Goal Programming pada Model}

Swiss-Belhotel dalam menjalankan fungsinya memiliki 19 orang resepsionis yang dibagi menjadi 2 bagian yaitu resepsionis yang ditugaskan di Hotel dan resepsionis yang ditugaskan di Villa. Daftar tamu di hotel lebih banyak dibandingkan dengan daftar tamu yang ada di Villa. Hal ini disebabkan mayoritas tamu menyukai letak bangunan Hotel yang berhadapan langsung dengan pantai Silae dibandingkan dengan letak bangunan villa yang tidak berdekatan dengan pantai. Sehingga pembagian jumlah resepsionis yang akan ditugaskan di Hotel lebih banyak yaitu berjumlah 12 orang sedangkan di Villa adalah 7 orang. Pada penelitian ini, penjadwalan yang akan dimodelkan dibatasi hanya penjadwalan resepsionis yang bertugas di Hotel saja yaitu yang kerjanya lebih sibuk daripada yang bertugas di Villa. (Data registrasi tamu Hotel dan Villa Swiss Bel Palu, 2013)

\subsubsection{Menentukan Fungsi Tujuan}

Fungsi tujuan yang diinginkan adalah untuk meminimalkan perawat ditugaskan pada shift malam, shift sore atau shift pagi secara berturut-turut melebihi range yang ditentukan.

\subsubsection{Menentukan Fungsi Pembatas dari Fungsi Tujuan}

Berdasarkan hasil wawancara dengan staff Swiss-Belhotel Palu, maka dapat dibuat batasan-batasan masalah yang terdapat dalam hotel. Dalam penjadwalan resepsionisnya, ada tiga kali waktu pergantian kerja/shift, yaitu pagi (shift 1), sore (shift 2) dan malam (shift 3). Resepsionis dibagi menjadi 4 tim yang masing-masing tim berjumlah 3 orang dan akan dijadwalkan pada tiga shift secara bergantian selama 1 bulan penjadwalan yang diusahakan penjadwalan tersebut akan berulang dalam 
jangka waktu 3 hari masa penjadwalan. Dalam sehari tim resepsionis tidak boleh dijadwalkan pada shift yang berurutan. Apabila 1 tim resepsionis berjaga pada shift malam, maka tim resepsionis tersebut tidak boleh berjaga pada shift pagi dihari berikutnya. Dalam setaip shift hanya ada 1 tim resepsionis yang bertugas. Tim resepsionis bertugas setidaknya 2 hari untuk masa penjadwalan 3 hari. Jumlah shift yang berjaga dalam 3 hari adalah 9 shift. Dari ilustrasi di atas, maka dapat diidentifikasikan permasalahan pokok yang yang dapat dijadikan sebagai batasan model dalam penjadwalan resepsionis di Swiss-BelHotel Palu.

\subsection{Menyelesaikan model Goal Programming menggunakan Software LINDO}

Berdasarkan fungsi tujuan dan fungsi pembatas yang diketahui maka dibuatkan model yang sesuai dengan permasalahan yang ada. Dengan menggunakan metode Goal Programming dan bantuan program LINDO akan diperoleh jadwal resepsionis untuk 3 hari.

\subsection{Interpretasi model}

Dalam proses perhitungan untuk mendapatkan solusi optimal digunakan aplikasi LINDO. Dari hasil perhitungan tersebut akan dibuat suatu jadwal setiap tim resepsionis selama 3 hari. Kemudian dibuat analisis untuk membandingkan perbedaan antara jadwal yang lama dengan yang baru.

\subsection{Tahap Kesimpulan}

Tahap terakhir dalam penelitian adalah menarik kesimpulan berdasarkan hasl analisis serta saran bagi penelitian lebih lanjut.

\section{HASIL DAN PEMBAHASAN}

\subsection{Hasil}

Untuk membuat model penjadwalan resepsionis yang optimal, maka akan dilakukan beberapa tahap yaitu mengumpulkan data kemudian membentuk model Goal Programming. Setelah model terbentuk maka model tersebut akan diselesaikan dengan menggunakan software LINDO yang akan menghasilkan jadwal resepsionis yang optimal.

\subsubsection{Pengumpulan Data}

Sebelum membentuk model Goal Programming, terlebih dahulu akan dilakukan pengumpulan data dari tempat studi kasusnya, yang dalam penelitian ini bertempat di Swiss-Belhotel Palu. Data diambil dari hasil wawancara penulis dengan beberapa staff resepsionis yang sedang bertugas. 
Tabel 1 : Jumlah Resepsionis dan Lama Jam Kerja Per Shift

\begin{tabular}{|l|l|c|}
\hline No & \multicolumn{1}{|c|}{ Data } & Keterangan \\
\hline 1 & Jumlah keseluruhan resepsionis di hotel & 12 \\
\hline 2 & Jumlah kebutuhan resepsionis per-shift & 3 \\
\hline 3 & Lama jam kerja shift pagi & $07.00-15.00(8 \mathrm{jam})$ \\
\hline 4 & Lama jam kerja shift sore & $15.00-23.00(8 \mathrm{jam})$ \\
\hline 5 & Lama jam kerja shift malam & $23.00-07.00(8 \mathrm{jam})$ \\
\hline
\end{tabular}

Sumber : Swiss-BelHotel Palu

\subsubsection{Membentuk Model Goal Programming}

Penerapan model Goal Programming pada penjadwalan resepsionis dilakukan dengan menggunakan bobot dan prioritas. Penyelesaian dilakukan dengan menentukan variabel keputusan, kendala tujuan, kendala sistem, bobot, prioritas, fungsi tujuan dan non negatif.

a. Variabel Keputusan

$$
\begin{aligned}
& X p_{i, j}=\left\{\begin{array}{l}
1, \text { jika tim resepsionis } j \text { bertugas untuk shift pagi pada hari } i \\
0, \text { jika tim resepsionis } j \text { tidak bertugas untuk shift pagi pada hari } i
\end{array}\right. \\
& X s_{i, j}=\left\{\begin{array}{l}
1, \text { jika tim resepsionis } j \text { bertugas untuk shift sore pada hari } i \\
0, \text { jika tim resepsionis } j \text { tidak bertugas untuk shift sore pada hari } i
\end{array}\right. \\
& X m_{i, j}=\left\{\begin{array}{l}
1, \text { jika tim resepsionis } j \text { bertugas untuk shift malam pada hari } i \\
0, \text { jika tim resepsionis } j \text { tidak bertugas untuk shift malam pada } \\
\text { hari } i
\end{array}\right.
\end{aligned}
$$

b. Kendala Tujuan

\section{Kendala Tujuan A}

Kendala ini memberikan ketentuan agar tim resepsionis tidak ditugaskan pada dua atau lebih shift kerja dalam sehari.

$X p_{i, j}+X s_{i, j}+X m_{i, j} \leq 1$

2. Kendala Tujuan B

Kendala ini memberikan ketentuan jika tim resepsionis ditugaskan pada shift malam di hari $i$ maka tim resepsionis tidak akan ditugaskan pada shift pagi di hari berikutnya. 


$$
X m_{i, j}+X p_{i+1, j} \leq 1
$$

3. Kendala Tujuan $\mathrm{C}$

Kendala ini memberikan ketentuan bahwa dalam setiap shift, hanya ada satu tim resepsionis yang bertugas.

$X p_{i, j}+X p_{i, j+1}+X p_{i, j+2}+X p_{i, j+3} \leq 1$

4. Kendala Tujuan D

Kendala ini memberikan ketentuan agar tim resepsionis bertugas setidaknya 2 hari.

$\sum_{i=1}^{3} X p_{i, j}+\sum_{i=1}^{3} X s_{i, j}+\sum_{i=1}^{3} X m_{i, j} \geq 2$

c. Kendala Sistem

Kendala ini memberikan ketentuan agar jumlah shift yang berjaga dalam 3 hari adalah 9 shift.

$\sum_{i=1}^{3} \sum_{j=1}^{4} X p_{i, j}+X s_{i, j}+X m_{i, j}=9$

d. Pemberian Bobot dan Prioritas

Pembobotan terjadi dikarenakan adanya pertimbangan bahwa setiap kendala memiliki tingkat kepentingan yang berbeda dalam pengoptimalannya. Sehingga perlu membuat bobot di setiap deviasi yang ada. Bobot yang dianggap lebih tinggi atau lebih penting diberikan nilai yang lebih besar. Adapun yang merupakan kriteria dan nilai bobot dalam permasalahan ini adalah:

Tabel 2 : Kriteria Bobot dan Prioritas Jadwal Sederhana

\begin{tabular}{|c|l|c|c|}
\hline Kendala & \multicolumn{1}{|c|}{ Kriteria Bobot dan Prioritas } & $\boldsymbol{d}_{\boldsymbol{i}}^{+}$ & $\boldsymbol{d}_{\boldsymbol{i}}^{-}$ \\
\hline A & $\begin{array}{l}\text { Tim resepsionis tidak dapat ditugaskan pada dua } \\
\text { shift berturut-turut dalam sehari. }\end{array}$ & 1 & 5 \\
\hline B & $\begin{array}{l}\text { Tim resepsionis tidak dapat ditugaskan shift malam } \\
\text { pada hari } i \text { kemudian kembali ditugaskan shift pagi } \\
\text { pada hari berikutnya secara berturut-turut }\end{array}$ & 2 & 5 \\
\hline C & $\begin{array}{l}\text { Dalam setiap shift, hanya ada satu tim resepsionis } \\
\text { yang bertugas. }\end{array}$ & 3 \\
\hline D & $\begin{array}{l}\text { Setiap tim resepsionis bertugas setidaknya dua } \\
\text { hari. }\end{array}$ & 4 \\
\hline
\end{tabular}


e. Fungsi Tujuan

Adapun fungsi tujuan dalam pemodelan ini bertujuan meminimalkan jumlah resepsionis yang bekerja lebih dari standar kebutuhan resepsionis, yaitu resepsionis ditugaskan pada shift pagi, sore atau malam secara berturut-turut melebihi range yang ditentukan. Fungsi tujuan penjadwalan yang menggunakan bobot dan prioritas adalah sebagai berikut:

Meminimumkan $\mathrm{Z}=\sum_{i=1}^{m} P_{k} W_{k i}\left(d_{i}^{+}+d_{i}^{-}\right)$

f. Menentukan Keperluan Non Negatif

Seperti dalam program linier, variabel-variabel model program tujuan ganda biasanya bernilai lebih besar atau sama dengan nol (Tambunan, 2012) [3]. Semua model program tujuan ganda terdiri dari variabel simpangan dan variabel keputusan, sehingga pernyataan non negatif dilambangkan:

$X_{1}, X_{2}, \cdots, X_{36} \geq 0$

$d_{1}^{+}, d_{2}^{+}, \cdots, d_{33}^{+} \geq 0$

$d_{1}^{-}, d_{2}^{-}, \cdots, d_{33}^{-} \geq 0$

g. Menyelesaikan dengan LINDO

Setelah menentukan setiap komponen yang dibutuhkan, setiap kendala tujuan dan fungsi tujuan diketikkan ke dalam bahasa program LINDO. Kemudian akan diperlihatkan jadwal yang telah dibuat, apakah ada yang melanggar pertimbangan yang dimasukkan atau tidak. Dari hasil penyelesaian menggunakan $\angle I N D O$, diperoleh jadwal resepsionis yang dapat disajikan dalam tabel:

Tabel 3 : Hasil Penjadwalan Resepsionis dengan Model Goal Programming

\begin{tabular}{|c|c|c|c|c|}
\cline { 3 - 5 } \multicolumn{2}{c|}{} & \multicolumn{3}{c|}{ Hari } \\
\cline { 3 - 5 } \multicolumn{2}{c|}{} & $\mathbf{1}$ & $\mathbf{2}$ & $\mathbf{3}$ \\
\hline \multirow{3}{*}{ Resepsionis } & $\mathbf{1}$ & Malam & Libur & Pagi \\
\cline { 2 - 5 } & $\mathbf{2}$ & Libur & Pagi & Malam \\
\cline { 2 - 5 } & $\mathbf{3}$ & Pagi & Malam & Sore \\
\cline { 2 - 5 } & $\mathbf{4}$ & Sore & Sore & Libur \\
\hline
\end{tabular}

Dari Tabel 3 dapat disimpulkan bahwa:

1. Tim resepsionis tidak ditugaskan pada dua shift dalam sehari (kendala $A$ terpenuhi). 
2. Jika tim resepsionis $j$ ditugaskan pada shift malam di hari $i$, maka tim resepsionis $j$ tidak akan ditugaskan shift pagi pada hari berikutnya (kendala B terpenuhi).

3. Setiap shift, hanya ada satu tim resepsionis yang bertugas (kendala C terpenuhi).

4. Tim resepsionis bertugas setidaknya 2 hari (kendala $D$ terpenuhi).

5. Jumlah shift yang menugaskan tim resepsionis dalam 3 hari adalah 9 shift (kendala sistem terpenuhi).

\subsection{Pembahasan}

Setelah model matematik diformulasikan dalam bentuk Goal Programming dan selanjutnya diproses dengan menggunakan program LINDO maka dihasilkan jadwal kerja resepsionis dalam periode 3 hari. Nilai "1" pada output LINDO mengartikan bahwa tim resepsionis $i$ akan bertugas pada hari $i$, sedangkan jika bernilai " 0 " berarti tim resepsionis $i$ tidak akan bertugas pada hari $i$.

\subsubsection{Jadwal Goal Programming}

Dari jadwal Goal Programming yang dimodelkan pada Tabel 3, jumlah kebutuhan resepsionis untuk tiap shift dalam satu hari sudah memenuhi range yang ditentukan pihak manajemen hotel yaitu sebanyak 3 resepsionis. Untuk setiap resepsionis dari jadwal Goal Programming hasil komputasi dengan menggunakan bobot dan prioritas tidak terdapat pelanggaran terhadap tim resepsionis yang ditugaskan pada dua shift kerja dalam sehari, artinya masing-masing tim hanya ditugaskan satu shift saja dalam sehari.

Untuk pelanggaran tim resepsionis $j$ yang ditugaskan pada shift malam di hari $i$, maka tim resepsionis $j$ tidak akan ditugaskan pada shift pagi dihari berikutnya tidak didapati pada model jadwal Goal Programming. Artinya setiap tim yang ditugaskan pada shift malam di hari $h$, maka tim tersebut tidak akan ditugaskan pada shift pagi dihari berikutnya. Tim yang mendapatkan tugas pada shift malam, minimal akan ditugaskan pada shift sore atau shift malam di hari berikutnya.

Adapun pelanggaran terhadap kendala untuk setiap shift hanya ada satu tim resepsionis yang bertugas, juga tidak didapati pada model penjadwalan menggunakan Goal Programming hasil komputasi ini. Demikian juga halnya dengan kendala tim resepsionis bertugas setidaknya dua hari. Pelanggaran terhadap kendala ini tidak 
terlihat pada jadwal yang dihasilkan oleh model Goal Programming. Artinya masingmasing tim resepsionis sudah mendapatkan jatah kerja minimal 2 hari.

\subsubsection{Perbandingan Jadwal Goal Programing dengan Jadwal Hotel}

Jadwal manual resespsionis yang digunakan hotel akan dibandingkan dengan jadwal dari Goal Programming dengan bantuan program LINDO berdasarkan pelanggaran yang dilakukan terhadap peraturan-peraturan hotel yang telah dikemas menjadi kendala tujuan dan kendala sistem.

1. Pada jadwal manual, kebutuhan resepsionis tiap shift telah memenuhi range yang ditentukan, sama halnya dengan jadwal dari model yang dihasilkan Goal Programming dengan bantuan LINDO. Kedua jadwal sama-sama telah memenuhi ketentuan pihak manajemen hotel yang menugaskan resepsionis pada tiap-tiap shiftnya berjumlah 3 orang.

2. Kedua jadwal baik jadwal Goal Programming maupun jadwal manual yang dipakai hotel menjadwalkan masing-masing tim resepsionis mendapatkan satu shift dalam sehari sesuai dengan kendala yang dibuat.

3. Pada jadwal manual, masih terdapat pelanggaran terhadap kendala tim resepsionis ditugaskan shift malam pada hari $i$, maka tidak akan ditugaskan pada shift pagi pada hari berikutnya. Dalam jangka waktu penjadwalan 3 hari, terdapat 2 kali pelanggaran terhadap kendala tersebut, yaitu terjadi pada tim resepsionis 2 yang ditugaskan pada shift malam di hari ke-2 dan kembali ditugaskan pada shift pagi di hari ke-3. Hal yang sama juga terjadi pada tim resepsionis 4 yang ditugaskan pada shift malam di hari ke-1 dan kembali ditugaskan pada shift pagi di hari ke-2. Adapun pada jadwal Goal Programming baik yang menggunakan bobot dan prioritas maupun yang tidak menggunakan bobot dan prioritas dalam jangka waktu penjadwalan 3 hari, tidak terdapat pelanggaran terhadap kendala tersebut.

4. Untuk kendala setiap shift, hanya ada satu tim resepsionis yang bertugas, baik jadwal manual dan jadwal Goal Programming tidak satupun pelanggaran yang terjadi. Keduanya memenuhi kendala ini.

5. Jadwal manual dan jadwal goal programming hasil komputasi sama-sama memenuhi kendala tim resepsionis bertugas setidaknya 2 hari dalam jangka waktu 3 hari penjadwalan.

6. Untuk kendala sistem, pada jadwal manual terdapat lebih dari 9 shift kerja yang dijadwalkan untuk resepsionis dalam jangka waktu penjadwalan 3 hari. Sedangkan pada jadwal Goal Programming batasan kendala sistem ini telah 
terpenuhi, artinya tidak terjadi pelanggaran pada kendala jumlah shift yang bertugas dalam 3 hari adalah 9 shift.

\section{KESIMPULAN}

Berdasarkan hasil yang didapatkan dalam penelitian ini, maka dapat dibuat beberapa kesimpulan sebagai berikut:

1. Model yang dibentuk menggunakan metode Goal Programming dengan fungsi tujuan meminimumkan $X p_{i, j}+X s_{i, j}+X m_{i, j} \leq 1, \quad X m_{i, j}+X p_{i+1, j} \leq 1, \quad X p_{i, j}+X p_{i, j+1}+X p_{i, j+2}+$ $X p_{i, j+3} \leq 1, \quad \sum_{i=1}^{3} X p_{i, j}+\sum_{i=1}^{3} X s_{i, j}+\sum_{i=1}^{3} X m_{i, j} \geq 2$ dengan $X p_{i, j}$ adalah tim resepsionis $j$ bertugas untuk shift pagi pada hari $i, X s_{i, j}$ adalah tim resepsionis $j$ bertugas untuk shift sore pada hari $i$ dan $X m_{i, j}$ adalah tim resepsionis $j$ bertugas untuk shift malam pada hari $i$.

2. Jadwal yang dihasilkan dari pemodelan metode Goal Programming dapat memenuhi setiap pertimbangan atau aturan yang ditetapkan hotel maupun resepsionis secara bersamaan.

3. Dengan menggunakan model penjadwalan Goal Programming, maka diperoleh penjadwalan yang lebih baik dibandingkan jadwal yang dibuat secara manual.

\section{DAFTAR PUSTAKA}

[1]. Agustina, R., 2012, Tugas-tugas Resepsionis, (http://riaagustina200.blogspot.com /2012/04/tuga-tugas-resepsionis.html), diakses 11 Maret 2014.

[2]. Soekartawi, 1995, Multi Objective Goal Programming (Program Tujuan Ganda) Teori dan Aplikasinya, PT. Grasindo, 1995, Jakarta, Hal 1.

[3]. Tambunan, S. A., 2012, Model Penjadwalan Dinas Jaga Perawat IGD Menggunakan Metode Goal Programming, Lembaga Penerbitan Universitas Sumatera Utara, 2012, Medan, Hal 53. 